\title{
Tecnologia e Mundialização
}

\author{
Igor Zanoni Constant Carneiro Leão*
}

RESUMO - A utopia de uma sociedade humana governada conscientemente de forma conjunta superando os velhos localismos e os preconceitos herdados do período medieval e ainda persistentes em diversos autores e instituições foi criada por autores modernistas a partir do iluminismo, entre os quais se destacam Marx, Engels e Nietzsche. Estes autores possuem uma visão anti-burguesa, mas souberam ver o potencial de progresso econômico, técnico e científico que caracteriza o capitalismo. Todavia, a construção de um mundo unido ou bem ordenado em termos econômicos, culturais ou outros continua uma utopia, dando lugar, hoje, a uma série de interrogações sobre o futuro da humanidade.

Palavras-chave: Mundialização. Pensamento moderno. Economia e cultura contemporâneas.

Como sabem os que estudam história econômica e as relações entre economia e ética, entre os séculos XII e finais do XVIII ocorreram na Europa dois movimentos convergentes que acabaram dando à luz as modernas sociedades industrias e liberais que hoje são um paradigma pregado por muitos intelectuais e instituições prestigiosas para todo o globo. Esse paradigma seria capaz de gerar um atraente cosmopolitismo baseado na integração econômica, financeira e cultural, tal como o paradigma extremado no chamado Consenso de Washington, mas em alguma medida faz parte da agenda de qualquer país politicamente significante no mundo, dado o modo impositivo como as coisas acabam se dando. Um bom exemplo são países de culturas ancestrais como a Índia e a China, que sobreviveram ao colonialismo e à brutalidade do Ocidente mediante uma cuidada modernização econômica e social, com toques mais ou menos claros de socialismo e planejamento bem como de potencial bélico, mas também mantendo suas tradições culturais impossíveis de serem erradicadas do cotidiano de seus povos. Sua modernização, todavia, conviveu com a violência estatal, especialmente na China, e com violência política de raízes étnicas e religiosas na Índia.

Aqueles dois movimentos foram, em primeiro lugar, o declínio lento do modo de produção feudal, que segundo os melhores autores, como Maurice Dobb, em seu clássico $A$

\footnotetext{
* Doutor em Economia pela UNICAMP. Professor do departamento de Economia pela Universidade Federal do Paraná (UFPR). Endereço eletrônico: igorzaleao@yahoo.com.br
} 
Evolução do Capitalismo, deveu-se a uma incompatibilidade de fundo entre os laços de produção servis e a capacidade de sustentação desses laços pela criação de adequadas forças produtivas que permitissem fenômenos como o crescimento do número de senhores e de servos numa Europa com uma geografia muito diferente da que é hoje. Esses fenômenos devem-se especialmente ao fato de o feudalismo procurar aumentar a produção agrícola mediante a coerção também aumentada sobre o trabalho do camponês, ao mesmo tempo em que a pequena mercantilização da produção não encontrava estímulo no artesanato local, que também se tornava medíocre e rotineiro. Sabe-se que em toda a Idade Média poucos avanços técnicos importantes foram feitos, como o moinho de água, a rotação de cultivos e a forma de prender $\mathrm{o}$ arado aos animais. Noutros termos, o feudalismo não era propenso ao desenvolvimento da técnica como a conhecemos hoje.

O segundo movimento foi o lento avanço das atividades mercantis e financeiras a partir do Mediterrâneo com as cidades italianas mais importantes e bem situadas rumo a toda a Europa, criando uma densa rede de relações entre regiões distantes, até mesmo a Ucrânia e a Rússia que produziam peles e madeira, entre outros produtos primários. A Europa unida por banqueiros, moedeiros e mercadores incentivou o nascimento das cidades em sua rota, que logo passaram a ser disputadas em termos políticos como um espaço independente de senhores e nobres. Elas permitem também o surgimento de instituições como as universidades que começam a tentar fazer uma síntese da Europa que emergia. A dramaticidade destas transformações fica clara nos inúmeros movimentos de contestação à ordem social e espiritual vigente, como se vê mesmo na vocação de São Francisco, suas hesitações e mesmo sua incompreensão do que ocorria e do que se esperava dele. Nas universidades processa-se com ordens religiosas novas como os dominicanos e os franciscanos em conflito com as antigas uma nova visão do mundo e da humanidade, que veio a ser laboriosamente construída com a escolástica, graças à retomada do pensamento aristotélico que o contato com os muçulmanos na Península Ibérica permitiu.

Esse estado de coisas, que envolve a disputa entre o Imperador e o Papa, a emergência problemática de um governo que conflita com o antigo governo da Fé, embora o Imperador tivesse de ser sagrado pelo Papa, desenvolve uma ciência que tenta conciliar razão e fé, numa síntese que tem raízes problemáticas tanto em Aristóteles como na tradição cristã. Mais adiante se perceberá os limites dessa tentativa e ambas se divorciarão no pensamento de Guilherme de Ockham e de Duns Scotto. Há aí uma tentativa de dar liberdade ao novo 
mundo que nascia em termos filosóficos e religiosos. Essa tentativa continuará no grande momento da Reforma do século XV.

A base material dessa sociedade em transformação todavia muda forçando os limites de alguma forma presentes na base antiga. Procura-se drenar pântanos, abrir novas áreas de cultivo, melhorar os transportes, ampliar as bases do artesanato criando a manufatura, bem como mudar plantações em pastagens, aumentar a produção de bens de grande valor como os têxteis, aperfeiçoar as ferramentas com as quais trabalha o artesão, mais tarde, abrindo a partir do século XV a exploração colonial com todas as conseqüências até hoje não totalmente concluídas. Cria-se uma forma de Estado complexa, o Antigo Regime, assentado na antiga nobreza feudal, nos privilégios, nos monopólios, no poder absoluto, na exploração colonial que incluiu o trabalho compulsório e na destituição das massas de seus meios de produção tradicionais. Essas e outras mudanças apóiam-se nas rodas poderosas do comércio e das finanças, bem como do poder monárquico absoluto, mas também, em termos técnicos, no braço humano do trabalhador mesmo quando qualificado e pior quando desqualificado ou escravo, no qual encontra seus limites técnicos que só seriam rompidos com a maquinaria e a fábrica, bem como a tecnificação das atividades agrícolas.

Neste longo percurso, o mais importante é a descoberta que homens fazem de outros homens e de outras sociedades. Isto ocorre quando Marco Pólo e seus parentes visitam a corte de Kublai Khan, ou quando São Francisco conversa com o Sultão Saladino e amplifica-se com a descoberta e a colonização do Oriente e do Ocidente com que se deparou Cristóvão Colombo. Esses contatos tornam-se permanentes e perpassados por laços mercantis e de poder, mas também originam uma visão cosmopolita que se vai completar na Ilustração, apesar das dificuldades com que Voltaire encontra para compreender outros povos e outras religiões. O século XVIII é pródigo em muitas descobertas diferentes do homem, por todos os oceanos e terras do planeta. Por outro lado, na própria Europa o homem ganha em muitos países direitos naturais com os quais se faz cidadão dotado de razão e com direitos à liberdade, à igualdade e à fraternidade dos outros homens. Numa chave religiosa, algo parecido ocorrera na época da Revolução Inglesa, de 1640.

Esse cosmopolitismo e essa nova visão do homem em todos os lugares onde se possa mostrar-lhes sua humanidade, tem um pé firme no avanço da técnica e da produção em que se observa por todo o século XVIII com o grande avanço da manufatura e da divisão técnica e social do trabalho, que acabam rompendo os limites estabelecidos e originam a Revolução Industrial já a partir de 1780 na Inglaterra e no início do século XIX, na França e 
nos Estados Unidos. Nesse momento, cria-se, a rigor, um novo modo de produção baseado na máquina e no trabalhador que é seu auxiliar mas não mais do que isso. $\mathrm{O}$ trabalho humano deixa de ser um limite ao aumento da produção, bem como dos negócios e dos lucros, e o progresso técnico passa a ser uma engrenagem lastreada na ciência com vistas à acumulação de capital. Neste momento consolida-se no Ocidente uma visão liberal que se perpetua com mudanças até hoje, embora posteriormente a transição do Antigo Regime para o capitalismo tenha-se feito às vezes de forma democrática como na França e nos Estados Unidos, noutras de forma autoritária, como na Alemanha e no Japão, e - por que não? - no Brasil, já no século XX de forma específica e tardia. Essa ordem liberal mundial esteve próxima de existir quase totalmente sob a hegemonia inglesa no século XIX e norte americana no século XX, mas hoje encontra-se matizada pelas estratégias de desenvolvimento econômico e de poder de países como a China, a Índia, a África do Sul e mesmo o Irã e a Venezuela, que colocam a imagem de um mundo distinto do que esperavam os teóricos do neoliberalismo. Todavia, de uma forma que passa por muitas estratégias nacionais, temos um mundo cada vez mais cosmopolita e integrado, seja do ponto de vista econômico como no da produção de bens culturais, embora as distintas regiões do globo procurem firmar-se a partir do que nelas é mais específico embora não pacífico, como por exemplo o estado de bem estar europeu ou o desejo de barrar o avanço americano no Oriente no caso do Irã e de outros países.

Esse cosmopolitismo tem, portanto, diversas matrizes ideológicas desde seu nascimento. À direita podemos colocar uma ordem liberal extremada, à esquerda, a utopia do Manifesto Comunista conclamando a união do proletariado mundial. Para os economistas que raro lêem livros de filosofia, é surpreendente ver as nuances com que grandes filósofos procuraram ver a possibilidade de um mundo unido. Tomemos o caso de Friedrich Nietzsche em uma de suas maiores obras, Humano, Demasiado Humano, de 1878, filósofo anti-burguês mas não socialista, Nietzsche rebela-se contra os resquícios de dogmática religiosa presentes em Kant e especialmente em Schopenhauer, no que há de anti-histórico e tradicional em sua metafísica. Para ele, o maior significado da era moderna reside no fato de poderem ser comparadas e vividas simultaneamente as diversas concepções do mundo, os costumes, as culturas algo impossível com a localização de cada cultura a seus espaços políticos e geográficos. Assim, "Quanto menos os homens estiverem ligados pela tradição, tanto maior será o movimento interior dos motivos, e tanto maior, correspondentemente, o desassossego exterior, a interpenetração dos homens, a polifonia dos esforços. Para quem ainda existe, atualmente, a rígida obrigação de ligar a si e a seus descendentes a um lugar? Para quem ainda 146

Economia \& Tecnologia - Ano 04, Vol. 12 - Jan./Março de 2008 
existe algum laço rigoroso? Assim como todos os estilos de arte são imitados, um ao lado do outro, assim também todos os graus e gêneros de moralidade, de costumes e de culturas."

Para Nietzsche, é uma era de confrontos e decisões culturais e morais, em que está implícita o sofrimento, que não deve ser evitado de se erguer através de uma cultura da comparação para as culturas nacionais fechadas, superando a ambas. Nesse sentido, os homens na cultura antiga se desenvolviam inconsciente e acidentalmente, hoje, podem fazê-lo conscientemente criando condições melhores para procriação dos indivíduos, sua alimentação, sua educação, sua instrução, podem economicamente gerir a Terra como um todo, ponderando, imobilizando as forças individuais umas frente às outras. Trata-se uma cultura consciente.

Assim, como Kant e outros pensavam num deus que dirige os destinos do mundo e o conduz à sua meta, os próprios homens devem estabelecer para si objetivos ecumênicos, abrangendo toda a Terra. Todavia, não se trata de uma harmonia universal que tem de produzir-se inerentemente por leis naturais de aperfeiçoamento. Esse desígnio supõe um governo global consciente tendo, como critério científico para objetivos ecumênicos um conbecimento das condições da cultura ainda por realizar. Essa seria a tarefa dos grandes espíritos do próximo século.

Tal visão é herdeira da Reforma bem como dos movimentos de liberdade de espírito semelhantes como os do Renascimento, com seu pendor para a ciência. Mas ela só se afirma na medida em que o espírito científico puder se fortalecer, superando os resquícios metafísicos da filosofia e da moral, como se vê em Schopenhaeur. Nietzsche substitui essa concepção do mundo do homem ainda cristã e medieval pela concepção histórica que o Iluminismo trouxa consigo na trajetória que pode ser sintetizada com três nomes: Petrarca, Erasmo, Voltaire. Essa visão não é nem pessimista nem otimista, propõe uma tarefa histórica que substitui a representação do mundo através da religião ou da arte por sua transformação histórica mediante a ciência, chegando perto da real essência do mundo e de seu conhecimento.

Os parágrafos acima mostram uma incrível semelhança entre alguns pontos desenvolvidos no Manifesto, por Marx, Engels e Nietzsche. Há a mesma mistura de intuições críticas e utopias radicais, a mesma fé numa humanidade unida pela ciência fazendo conscientemente sua história, como se esperaria em autores modernistas como são todos. Essas utopias partem das conquistas do capitalismo como um mecanismo fantástico de criação e destruição, de compulsivo ir adiante, desmanchando no ar tudo que é sólido. Essa 
mesma idéia, aliás, foi retomada mais tarde por Joseph Schumpeter. Vê-se em todos os autores a demanda da moderna vida econômica por crescimento e progresso, a expansão dos desejos humanos para além de fronteiras geográficas e morais, a compulsão sobre as pessoas a explorarem a si e aos outros. Essa relação de autores deveria incluir Goethe quando pensa que a moderna sociedade burguesa estava fazendo nascer uma cultura mundial. Essa idéia é retomada deste autor por Marx e Engels no Manifesto quando indicam:

"Em lugar das velhas carências, satisfeitas pela produção interna, enfrentamos agora novas carências que exigem, para sua satisfação, produtos de terras e climas distantes. Em lugar da velha auto-suficiência local e nacional, deparamos, em todas as direções, com a interdependência universal. Tanto na produção material como na espiritual (geistige). As criações espirituais de nações individualizadas se tornam propriedade comum. O bitolamento e unilateralidade das nações se tornam cada vez mais impossíveis, e das várias literaturas nacionais e locais brota uma literatura mundial."

Como assinala Marshall Berman, no século XX em muitos países procurou-se alcançar as realizações das sociedades modernas enfrentando ao mesmo tempo a fragmentação e desunião através de objetivos nacionais comuns. A modernização caminha ao lado de um freio político e espiritual que mantenha laços de solidariedade entre governantes e governados. É possível que em parte isso responda a uma tentativa de reprimir o espírito crítico do seu próprio povo. De qualquer modo, há uma tensão entre o pensamento crítico e a livre imaginação e a necessidade de flutuar no mercado mundial. Indo mais fundo nessa questão, levanta-se o problema do que é exatamente uma comunidade política no mundo moderno e o que exatamente os seres humanos podem partilhar neste mundo. Essa questão, para Berman, tem sido levantada de forma inconclusiva por Herbert Marcuse e Hannah Arendt.

Seja como for, parece claro que os modernistas não puderam resolver satisfatoriamente as questões culturais e políticas das nações modernas e suas relações com o mercado. Nietzsche e Marx perecem pensar num governo mundial e numa cultura do futuro, escoradas nos avanços, legados a este futuro pelo capitalismo, o qual, entretanto, precisa ser superado, para que os homens possam controlar sua história. Nada disso é óbvio mas fez e pode fazer sentido. Entretanto, a busca da verdade e da ciência, a fuga da representação, podem se tornar temíveis. Pensemos não apenas nos enormes danos ambientais que o planeta vem sofrendo, as ambigüidades morais entre outras do avanço tecnológico, hoje no limiar de criar artificialmente a vida, e os limites existenciais sofridos pelos seres humanos quando são 
incapazes de dar sentido às suas próprias experiências de vida, o que torna a colocar os problemas dos nexos de solidariedade e cultura comum entre os membros de cada nação e as relações com o conjunto da humanidade. Não importa apenas a verdade, importa o sentido da vida. Sem ser conservador, o niilismo dos mercados e a submissão da ciência à sua lógica devem dar lugar à preocupação também inscrita na tradição modernista com a produção cultural e a liberdade de pensamento, tão ao gosto de Marx quanto de Nietzsche, bem como com a necessidade de controles sociais públicos e democráticos, tanto no âmbito de cada país como do ponto de vista de um mundo generoso e possível.

\section{REFERÊNCIAS}

ARENDT, H. A condição humana. Forense Universitário. $7^{a}$ edição, 1995.

BERMAN, M.Tudo que é sólido desmancha no ar: a aventura da modernidade. Companhia das Letras, 1986.

DOBB, M. A evolução do capitalismo. Coleção Os Economistas, Editora Abril, 1986.

MARX, K. \& ENGELS, F. Manifesto comunista. Diversas edições.

MOORE JÚNIOR, B. As origens sociais da ditadura e da democracia: senhores e camponeses na construção do mundo moderno. Edições Cosmos, Livraria Martins Fontes, 1 Edição (1967)

NIETZSCHE, F. Humano, demasiado humano: um livro para espíritos livres. Companhia das Letras. 2005.

SCHOPENHAUER. A. Coleção os pensadores. 1972.

SCHUMPETER, J. Capitalismo, socialismo e democracia. Zahar, 1984. 
